\title{
Successful cardiopulmonary bypass in diabetics with anaphylactoid reactions to protamine
}

\author{
W S WALKER, K G REID, C F HIDER, I A DAVIDSON, F E BOULTON, P L YAP \\ From the Department of Cardiothoracic Surgery and Blood Transfusion Service, Edinburgh Royal Infarmary, \\ Edinburgh
}

SUMmaRY Two insulin dependent diabetics with previous anaphylactic like (anaphylactoid) reactions to protamine underwent successful cardiopulmonary bypass for coronary artery surgery. Platelet concentrates instead of protamine were used to neutralise their systemic heparinisation. In both cases the anaphylactoid reactions first became apparent after administration of protamine sulphate at the end of cardiac catheterisation. These cases show that adverse reactions to protamine need not be a contraindication to cardiopulmonary bypass and cardiac surgery and emphasise that this condition should be considered in all patients with a history of previous protamine exposure or one which may be associated with anaphylactoid reactions to protamine.

Anaphylactic like (anaphylactoid) reactions to protamine, a polycationic polypeptide derived from salmon sperm, are relatively uncommon. They have been reported in patients with fish allergy 12 and in those previously exposed to protamine, principally diabetics who have received protamine zinc insulin 34 but also filtration leucapheresis donors who may have received protamine sulphate to neutralise heparin used as an anticoagulant during this procedure. ${ }^{24}$ Both vasectomised and infertile men have a theoretical risk of sensitivity via antibodies raised to protamine contained in sperm released into the blood stream, ${ }^{5}$ though this remains to be clinically confirmed.

Anaphylactic reactions to protamine which have been reported include potentially fatal $\operatorname{IgE}^{134}$ mediated anaphylaxis with severe bronchospasm hypotension, urticaria and angioneurotic oedema, ${ }^{2}$ and local cutaneous reactions. ${ }^{6}$ Protamine may cause adverse reactions by several non-immunological routes including release of vasoactive platelet substances, degranulation of mast cells, activation of complement (reviewed by Lakin $e t a l^{6}$ ), and also by complement dependent IgG antibody. ${ }^{6}$

As protamine is normally used to reverse systemic

Requests for reprints to Mr W S Walker, Department of Cardiothoracic Surgery, Edinburgh Royal Infirmary, Edinburgh EH3 9YW.

Accepted for publication 6 March 1984 heparinisation during cardiopulmonary bypass, coronary artery surgery would normally be contraindicated in patients with serious anaphylactoid reactions to protamine. Platelets, however, are known to contain platelet factor $4,{ }^{7}$ which has potent antiheparin activity, ${ }^{8}$ and we therefore investigated the use of platelet concentrates instead of protamine for reversing the systemic heparinisation during cardiopulmonary bypass in two patients with a history of serious anaphylactoid reactions to protamine.

\section{Patients and methods}

\section{CASE REPORTS}

Case 1

A 33 year old woman (weight $60 \mathrm{~kg}$ ) with insulin dependent diabetes for 17 years and a strong family history of ischaemic heart disease was referred for elective surgery because of a two year history of increasing angina, predominantly of effort. She had received protamine zinc insulin previously, and after the administration of intravenous protamine sulphate at the end of cardiac catheterisation she developed flushing, nausea, and a fall of $30 \mathrm{~mm} \mathrm{Hg}$ in systolic blood pressure with associated tachycardia. These symptoms responded well to treatment with intravenous chlorpheniramine and hydrocortisone. Subsequent intradermal sensitivity testing using intradermal protamine sulphate compared with a normal saline control showed a flare reaction with doses above $0.1 \mu \mathrm{g}$ of protamine. Desensitisation was then attemp- 
ted using subcutaneous protamine sulphate injections. These began with $0.012 \mu \mathrm{g}$ of protamine in 0.1 $\mathrm{ml}$ of saline, and the protamine concentration was doubled with each succeeding dose. Six hourly injections were given until a dosage of $800 \mu \mathrm{g}$ of protamine was reached without any systemic reaction, although a $3.5 \mathrm{~cm}$ flare around the injection site was present. Three days later an intravenous test dose of $1000 \mu \mathrm{g}$ of protamine was given. This produced an immediate reaction with noticeable flushing, severe headache, tachypnoea, and, despite beta blockade for angina, a rise in pulse rate from 60 to 100 beats $/ \mathrm{min}$. Her symptoms again resolved with the intravenous administration of chlorpheniramine and hydrocortisone. She was therefore considered to be at risk of developing a serious anaphylactoid reaction to protamine sulphate, and the decision was made to proceed to cardiopulmonary bypass and cardiac surgery without the use of protamine sulphate to neutralise heparin.

At operation anticoagulation was achieved with 26000 units of heparin (300 units $/ \mathbf{k g}+800$ units in the pump prime) and reversed aortocoronary saphenous vein grafts were anastomosed to four coronary arteries. After bypass the prothrombin ratio was $1.5: 1$, partial thromboplastin time was $>120$ s (control $35 \mathrm{~s}$ ), and thrombin time (in saline) was $>60 \mathrm{~s}$ (control $11 \mathrm{~s}$ ). Six units of platelet concentrate and $400 \mathrm{ml}$ fresh frozen plasma were administered. She was retained in theatre for several hours to allow meticulous haemostasis. Postoperatively she required a further 12 unit infusion of platelet concentrate and a blood transfusion to replace a measured 41 loss through the drains, which were removed after 22 hours. She remained in intensive care for two days and was discharged to convalescence on the tenth postoperative day. At last review thirty nine months after surgery she was asymptomatic apart from mild ankle oedema.

\section{Case 2}

A 56 year old man (weight $76 \mathrm{~kg}$ ) with insulin dependent diabetes for 36 years, during which time he had been taking protamine zinc insulin, was admitted for urgent cardiac surgery because of unstable angina and a history of three previous myocardial infarctions. He had previously undergone uneventful cardiac catheterisation, but at repeat cardiac catheterisation after his third infarction he developed acute bradycardia, hypotension, vomiting, sweating, and wheezing immediately after intravenous protamine administration at the end of the procedure. This responded well to treatment with intravenous chlorpheniramine, hydrocortisone, and atropine. Although this episode represented the first direct evidence of an anaphylactoid reaction to protamine, nodules had been noted previously at his insulin injection sites.
Subsequently, he was given a monocomponent insulin regimen, and sensitivity testing with intradermal injections of protamine sulphate was undertaken. The test result was considered to be positive, with a pronounced flare response, at dosages $>1 \mu \mathrm{g}$ of protamine.

At operation anticoagulation was achieved with a total of 63000 units of heparin, this unit having adopted a policy of administering sufficient heparin to achieve an activated clotting time (Hemochron, International Technidyne Corporation, New Jersey, USA) of at least $450 \mathrm{~s}$ before bypass. ${ }^{9}$

Four coronary arteries were grafted and 6 units of platelet concentrate used to promote coagulation after cardiopulmonary bypass. Although the patient was kept in theatre to ensure complete haemostasis and $600 \mathrm{ml}$ of fresh frozen plasma had been given, heavy drainage necessitated reopening the chest 45 minutes after first closure. At this point his coagulation results were still abnormal with a prothrombin ratio of $1.5: 1$, partial thromboplastin time of $59.5 \mathrm{~s}$ (control $30.5 \mathrm{~s}$ ), and thrombin time (in saline) of 38.0 $s$ (control $10.5 \mathrm{~s}$ ). A further 6 units of platelets and $500 \mathrm{ml}$ of fresh frozen plasma were therefore given.

The drains were removed after 27 hours having drained a total of $2075 \mathrm{ml}$. Pulmonary oedema and the need for positive inotropic support led to a lengthy stay of 10 days in the intensive care unit, but thereafter he progressed well and was discharged to convalescence on the twenty-fifth postoperative day. At review 16 months postoperatively he was still asymptomatic.

\section{Discussion}

It seems probable that the number of patients presenting for cardiac surgery who are at risk of developing severe anaphylactoid reactions to protamine will rise in the short term because of the increasing number of insulin dependent diabetics who require coronary artery surgery, ${ }^{10}$ many of whom will have had previous exposure to protamine zinc insulin. With the decline in recent years in the use of this insulin this may eventually cease to be a problem. There will, however, remain patients who may be sensitised to protamine by other mechanisms - such as those with fish allergy - and the long term effect of vasectomy in this respect has yet to be established.

Because of the risk of a severe anaphylactic reaction with intravenous protamine administration at the end of cardiopulmonary bypass, we consider that any patient with a history of anaphylactoid reactions to protamine should be carefully assessed before surgery. Although doubt has recently been cast on the validity of intradermal testing for allergy, this has proved positive in patients previously exposed to pro- 
tamine zinc insulin, ${ }^{34}$ as indeed it did in our cases. Nevertheless, for those potentially allergic patients a small intravenous dose of protamine of 5-10 mg should be given to test for sensitivity. ${ }^{4}$

We used the antiheparin effect of platelet factor 4 in platelets to reverse systemic heparinisation since alternative heparin neutralising agents such as hexadimethrine are no longer generally available. Although successful cardiopulmonary bypass without heparin reversal has already been shown to be feasible, ${ }^{11}$ the level of heparinisation used in this study was very much lower than that currently used. Our experience suggests that even with the high levels of heparinisation required with membrane oxygenation, cardiopulmonary bypass is still possible with the use of platelet concentrates instead of protamine and that a history of serious anaphylactoid reactions to protamine should not therefore prevent access to cardiac surgery.

\section{References}

1 Knape JTA, Schuller JL, De Haan P, De Jong AP, Bovill JG. An anaphylactic reaction to protamine in a patient allergic to fish. Anesthesiology 1981; 55: 324-5.

2 Caplan SN, Berkman EM. Protamine sulfate and fish allergy [Letter]. $N$ Engl f Med 1976; 295: 172.
3 Moorthy SS, Pond W, Rowland RG. Severe circulatpry shock following protamine (an anaphylactic reaction)? Anesth Analg (Cleve) 1980; 59: 77-8.

4 Doolan L, McKenzie I, Krafchek J, Parsons B, Buxton B. Protamine sulphate hypersensitivity. Anaesth Intenside Care 1981; 9: 147-9.

5 Samuel T. Antibodies reacting with salmon and human protamines in sera from infertile men and from vasectomized men and monkeys. Clin Exp Immunol 1977; 30: $181-7$.

6 Lakin JD, Blocker TJ, Strong DM, Yocum MW. Anaphylaxis to protamine sulfate mediated by a complement-dependent IgG antibody. F Allergy Clin Imomunol 1978; 61: 102-7.

7 Holmsen H. Biochemistry of the platelet release reactions. In: Biochemistry and pharmacology of platelets. Ciba Foundation symposium 35 (new series). Amsterdam, New York: Elseveier/Excerpta Medica/North Holland, 1975: 175-275.

Blutgerinnung. Archiv fur experimentelle Pathologie und Pharmakologie 1954; 222: 107-53.

9 Young JA, Kisker CT, Doty DB. Adequate anticoagulation during cardiopulmonary bypass determined by activated clotting time and the appearance of fibrin monomer. Ann Thorac Surg 1978; 26: 231-40.

10 Salomon NW, Page US, Okies JE, Stephens J, Krause AH, Bigelow JC. Diabetes mellitus and coronary artery bypass. I Thorac Cardiovasc Surg 1983; 85: 264-71.

11 Castaneda AR. Must heparin be neutralized following open heart operations? F Thorac Cardiovasc Surg 1966; 52: 716-9. 